anxiety and excessive mental exertion; and in 1850 appeared his work on "Obscure Diseases of the Mind and Brain." It has passed through four editions. His next work was on "Light,' as influencing life and health. In 1848 he founded the "Psychological Journal," of which he was for sixteen years the sole proprietor and editor. This, the first periodical of its kind in this country, was succeeded by the " Medical Critic," of which he was also editor. Dr. Winslow 8 health had been failing for some time before his death; he had long suffered from kidney disease, and it would appear that he died from uræmic coma.

\title{
J. THOMPSON DICKSON, M.B. CANTAB.
}

An assiduous and promising worker in the field of medico-psychology has been removed by the death, from heart disease, of this young physician. Mr. Thompson Dickson died suddenly on January the 5th, in his thirty-third year. He was educated at Cambridge, where, having taken the degree of Master of Arts, he embraced the study of medicine. Guy's Hospital was the metropolitan school at which he pursued his clinical courses, and he took the diploma of the Royal College of Surgeons in 1863, the Licentiateship of the Apothecaries' Company in 1866, the degree of Bachelor of Medicine at Cambridge in 1867, and the Membership of the Royal College of Physicians in 1868. He became lecturer on mental diseases at Guy's, and his pupils always spoke highly of his prelections. He belonged to most of the medical societies, and occasionally took part in their discussions with spirit and effect. Among other contributions by him to this Journal was one on "Matter and Force in Relation to Mental and Cerebral Phenomena," and he contributed numerous papers on cognate subjects to "The Lancet" and other medical journals. He was the author of an anonymous criticism in the "British Medical Journal," entitled " A Social Blot," which, at the time, excited a good deal of just indignation in those members of the British Medical Association who were slandered by it. Epilepsy engaged a good deal of his attention, and he was employed in making observations as to its pathology and treatment at the time of his premature decease. He was a member of the Medico-Psychological Association, and at the last quarterly meeting exhibited several interesting microscopical specimens and drawings of morbid conditions of the brain and spinal cord. The publication of his lectures at Guy's Hospital has taken place since his death; the work has been noticed by us in this number of the Journal.

\section{Appointments.}

M'Dowall, J. G., M.B., C.M., has been appointed Assistant Medical Officer to the South Yorkshire Lunatic Asylum, Wadsley, rice Lowe.

M'DowaLL, T. W., M.D., L.R.C.S.Ed. (Assistant Medical Officer of the West Riding Lunatic Asylum, Wakefield), has been appointed Medical Superintendent of the Northumberland Lunatic Asylum, vice Wilson, deceased.

HERFORD, C.H., B.A., M.B., has been appointed Assistant Medical Officer to Moorcroft House Asylum, vice Elliott, resigned.

NewCOMBE, C. F., M.B., C.1!., has been appointed Clinical Assistant at the West Riding Lunatic Asylum, Wakefield, vice Wright.

SAVAGE, G. H., M.D., L.R.C.P.L., has been appointed Lecturer on Mental Diseases at Guy's Hospital Medical College, vice Dickson, deceased.

SARJANT, J. J., M.R.C.S.E., has been appointed Assistant Medical Officer at the Institution for the Insane, Coton-hill, Stafford, vice Yeats, resigned.

Wickham, R. H. B., Esq., Medical Superintendent Borough Asylum, Newcastle-on-Tyne, has been appointed Lecturer on Mental Disease at the University of Durham.

WRIGHT, F. W., M.R.C.S.E., has been appointed Assistant Medical Officer to the Royal Lunatic Asylum, Aberdeen, vice Paterson, resigned.

Wood, Thomas O., M.R.C.S.E, L.R.C.P.Ed. (late Medical superintendent of Dunston Lodge Asylum), has been appointed an Assistant Medical Officer of the Kent County Asylum. 